\title{
Erwinia chrysanthemi at high osmolarity: influence of osmoprotectants on growth and pectate lyase production
}

\author{
Gwenola Gouesbet, ${ }^{1}$ Mohamed Jebbar, ${ }^{1}$ Sylvie Bonnassie,' \\ Nicole Hugouvieux-Cotte-Pattat, ${ }^{2}$ Souad Himdi-Kabbab ${ }^{3}$ and \\ Carlos Blanco'
}

Author for correspondence: Carlos Blanco. Tel: +33992861 40. Fax: +3399286700.

e-mail: Carlos.Blanco@univ-rennes1.fr

\author{
1 CNRS URA 256, \\ Département Membranes \\ et Osmorégulation, \\ Université de Rennes I, \\ Campus de Beaulieu, \\ Avenue du Général \\ Leclerc, 35042 Rennes \\ Cedex, France \\ 2 CNRS URA 1486-1, \\ Laboratoire de Génétique \\ Moléculaire des \\ Microorganismes, INSA \\ Bát. 406, 20 Avenue Albert \\ Einstein, 69621 \\ Villeurbanne Cedex, \\ France \\ 3 CNRS URA 704, Groupe de \\ Recherche de \\ Physicochimie Structurale, \\ Université de Rennes I, \\ Campus de Beaulieu, \\ Avenue de Général Leclerc, \\ 35042 Rennes Cedex, \\ France
}

\begin{abstract}
The mechanism of osmotic stress adaptation was investigated in the phytopathogen Erwinia chrysanthemi. Growth of the bacterium was inhibited by elevated medium osmolarity, and exogenous glycine betaine, proline, ectoine or pipecolate permitted recovery of growth at inhibitory osmolarity. Osmoprotectants were taken up by transporters induced by elevated osmolarity, and their level of accumulation within the cell was dependent on the osmolarity of the growth medium. The influence of osmolarity and osmoprotectants on the production of pectate lyases (PLs) was investigated. Increased medium osmolarity resulted first in an induction of PL activity, followed by a shift to the basal level at higher osmolyte concentrations. This induction was reversed by osmoprotectants in the medium. The increased PL activity was attributed in part to the induced transcription of the main PL gene, pelE, and all the osmoprotectants that were analysed were found to prevent pelE induction. PL activity was partially inhibited in vitro by high ionic strength but not by elevated concentrations of sugars, and the addition of osmoprotectants at $1 \mathrm{mM}$ had no effect on PL activity in vitro.
\end{abstract}

\section{Keywords: Erwinia cbrysanthemi, osmoprotectants, pectate lyases, pel genes,} osmoadaptation

\section{INTRODUCTION}

Moisture was recognized by Colhoun (1973) to be an important factor in the infection of plants by pathogenic micro-organisms. A correlation between irrigation and stalk rot of maize suggested that Erwinia chrysanthemi is sensitive to desiccation (Hoppe \& Kelman, 1969). The phytopathogenic bacterium E. chrysanthemi produces extracellular pectate lyases (PLs) which attack components of the plant cell wall (Kotoujansky, 1987). The PL structural genes $(p e l)$ are organized in five independent operons grouped into two clusters on the bacterial chromosome (Kotoujansky, 1987). The influence of environmental conditions on the total pectinase production and on the expression of the individual pel genes was examined in E. chrysanthemi 3937 , and pel transcription proved to be sensitive to many conditions (Hugouvieux-Cotte-Pattat $e t$ al., 1992), and their differential expression was observed at

Abbreviation: PL, pectate lyase different medium osmolarities. The pelE gene, encoding the major pectate lyase, was strongly induced in the presence of $0.3 \mathrm{M} \mathrm{NaCl}$, while expression of the other pel genes was either not affected or was weakly repressed by elevated medium osmolarity (Hugouvieux-Cotte-Pattat $e t$ al., 1992). Recently, Prior et al. (1994) presented opposite results using different strains of E. chrysanthemi. These authors showed that secretion of PL in the extracellular medium decreased when water activity was reduced. However, this decrease in extracellular PL was linked to intracellular accumulation of PL. They also demonstrated that growth of $E$. chrysanthem $i$ is limited under osmotic stress and that this effect is reversed in presence of various osmoprotectants (Prior et al., 1994). Nevertheless they did not analyse the behaviour of osmoprotectants. We have previously shown (Talibart et al., 1994) that the mechanism of osmoprotection in Escherichia coli (Csonka, 1989; Csonka \& Hanson, 1991) is not applicable to all bacteria. Thus, we have analysed the mechanism(s) of osmoregulation in E. chrysantbemi strain 3937, especially the behaviour of various osmoprotectants within the cells, 
and have demonstrated that variations in PL production result from transcriptional induction of the pelE gene.

\section{METHODS}

Bacterial strains and growth conditions. Bacterial strains used in this study were E. chrysanthemi 3937 (wild-type) and its derivatives A1880 (pelC: : uid $A \mathrm{Km}$ ) and A1828 (pelE: : uid A $\mathrm{Km}$ ) (Hugouvieux-Cotte-Pattat et al., 1992). Cells were grown on LB medium or in minimal medium M63 (Miller, 1972) at $30^{\circ} \mathrm{C}$. Carbon sources were added at $2 \mathrm{~g} \mathrm{l}^{-1}$. Minimal media of elevated osmotic strength were made by adding $\mathrm{NaCl}, \mathrm{KCl}$, mannitol, sorbitol or glycerol, and the osmotic pressure was determined by measuring the freezing point with an osmometer. The osmoprotectants glycine betaine, proline, ectoine and pipecolate were generally supplied at a final concentration of $1 \mathrm{mM}$. Bacterial growth was monitored by $\mathrm{OD}_{\mathbf{5 7 0}}$.

Enzyme assays. Assays of total PL and $\beta$-glucuronidase were performed on toluene-permeabilized cultures grown to late exponential-phase to achieve maximal PL production. Total PL activity was determined by the degradation of polygalacturonate to unsaturated products that absorb at $235 \mathrm{~nm}$ (HugouvieuxCotte-Pattat et al., 1992); specific activity (U) is expressed as $\mu \mathrm{mol}$ unsaturated products liberated $\mathrm{min}^{-1}(\mathrm{mgdry} \mathrm{wt})^{-1} . \beta$ Glucuronidase activity was measured by following the degradation of the substrate $p$-nitrophenyl- $\beta$-D-glucuronide into $p$ nitropheno that absorbs at $405 \mathrm{~nm}$ (Hugouvieux-Cotte-Pattat et al., 1992); specific activity (U) is expressed as nmol $p$ nitrophenol liberated $\min ^{-1}$ ( $\mathrm{mg}$ dry $\left.\mathrm{wt}\right)^{-1}$. The results reported are the average of at least three independent experiments, and the SD was less than $10 \%$ in each case.

Uptake and behaviour of $\left[{ }^{14} \mathrm{C}\right]$ osmoprotectants. $\left[1,2-{ }^{14} \mathrm{C}\right] \mathrm{gly}-$ cine betaine was prepared from $\left[1,2-{ }^{14} \mathrm{C}\right]$ choline as described by Ikuta et al. (1977). [U- ${ }^{14} \mathrm{C}$ ]pipecolate was purified from a culture of Brevibacterium ammoniagenes ATCC 6872 supplied with $\left[{ }^{14} \mathrm{C}\right]$ lysine as described by Gouesbet et al. (1992). $\left[{ }^{14} \mathrm{C}\right]$ ectoine was biologically prepared from L- $\left[\mathrm{U}_{-}{ }^{14} \mathrm{C}\right]$ glutamic acid supplied to Brevibacterium linens A TCC 9175 as described by Jebbar $e t$ al. (1992). L-[U- $\left.{ }^{14} \mathrm{C}\right]$ proline $\left(9.84 \mathrm{GBq} \mathrm{mmol}^{-1}\right)$ was purchased from Amersham-France. Extraction of cellular solutes, paper chromatography, HPLC, electrophoresis and ${ }^{13} \mathrm{C}$ NMR analysis of cell extracts were described by Gouesbet et al. (1992) and Bernard et al. (1993). Uptake assays were carried out as described by Jebbar et al. (1992).

Determination of intracellular solute content. The osmoprotectant content of the cells was determined after growth in M63 medium for three generations, with various $\mathrm{NaCl}$ concentrations in the presence of $1 \mathrm{mM}\left[{ }^{14} \mathrm{C}\right]$ pipecolate $(0.9 \mathrm{MBq}$ $\left.\mathrm{mmol}^{-1}\right), 1 \mathrm{mM}\left[{ }^{14} \mathrm{C}\right]$ glycine betaine $\left(1.3 \mathrm{MBq} \mathrm{mmol}^{-1}\right), 1 \mathrm{mM}$ $\left[{ }^{14} \mathrm{C}\right]$ proline $\left(1 \cdot 1 \mathrm{MBq} \mathrm{mmol}^{-1}\right)$ or $1 \mathrm{mM}\left[{ }^{14} \mathrm{C}\right]$ ectoine $(0.6 \mathrm{MBq}$ $\left.\mathrm{mmol}^{-1}\right)$. Cells were collected by centrifugation $(3500 \mathrm{~g}$, $10 \mathrm{~min}$ ). After ethanolic solute extraction and electrophoretic separation of the soluble fraction (Gouesbet et al., 1992), the radioactivity of each spot was determined by scintillation counting. Twenty percent of the radioactivity was incorporated by the cells during the assay. Results are the mean of at least three independent experiments, and the SD was less than $10 \%$.

\section{RESULTS AND DISCUSSION}

\section{Behaviour of osmoprotectants in the cell}

The growth rate of E. chrysanthemi 3937 was analysed in M63 minimal medium supplemented with various concentrations of $\mathrm{NaCl}$. Growth was optimal in the absence of $\mathrm{NaCl}$ and was not significantly affected by up to

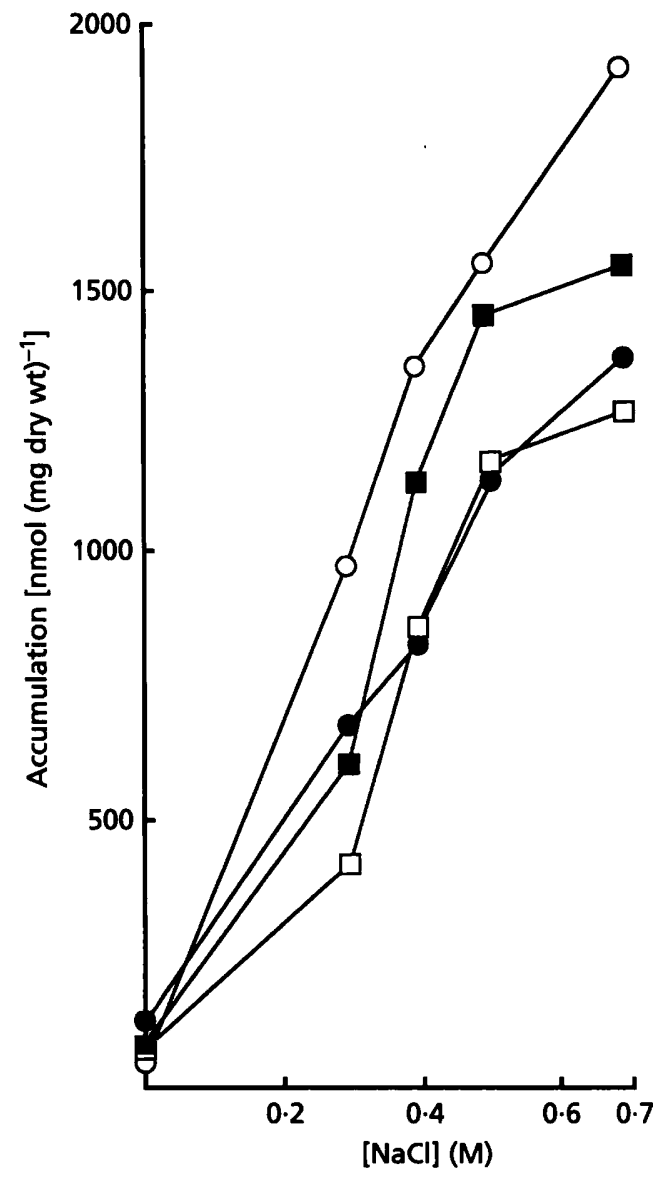

Fig. 1. Accumulation of exogenously supplied osmoprotectants in medium of increasing osmolarity. Cells were grown for three generations in M63 medium containing no salt or $0.3,0.4,0.5$ or $0.7 \mathrm{M} \mathrm{NaCl}$ in the presence of: $0,1 \mathrm{mM}\left[{ }^{14} \mathrm{C}\right]$ glycine betaine; $\square$, $\left[{ }^{14} \mathrm{C}\right]$ ectoine;,$\left[{ }^{14} \mathrm{C}\right]$ proline; or $\mathrm{D},\left[{ }^{14} \mathrm{C}\right]$ pipecolate.

$0.3 \mathrm{M} \mathrm{NaCl}$. Above this value the growth rate was dramatically reduced, and at concentrations greater than $0.6 \mathrm{M} \mathrm{NaCl}$ growth was totally inhibited. As previously described for various E. chrysanthemi isolates (Prior $e$ t al., 1994), the growth of E. chrysanthemi 3937 in medium of inhibitory osmolarity was improved by the presence of glycine betaine, proline or pipecolate. In addition, we observed that ectoine was as effective as glycine betaine in improving the growth of E. chrysanthemi 3937. These osmoprotectants were active at a very low concentration $(5 \mu \mathrm{M})$.

Uptake of glycine betaine, pipecolate and ectoine was observed only in cells grown in medium of high osmolarity, whereas low-level proline uptake was also observed in cells grown at low osmolarity. Uptake of osmoprotectants was inducible by osmolarity rather than by water activity, since the induction of uptake was observed on addition of $\mathrm{NaCl}, \mathrm{KCl}$, mannitol or sucrose, but not on addition of the freely diffusible compound glycerol.

${ }^{13} \mathrm{C}$ NMR analysis of ethanolic extracts of cells grown in medium containing $0.5 \mathrm{M} \mathrm{NaCl}$ and $1 \mathrm{mM}$ of the various 


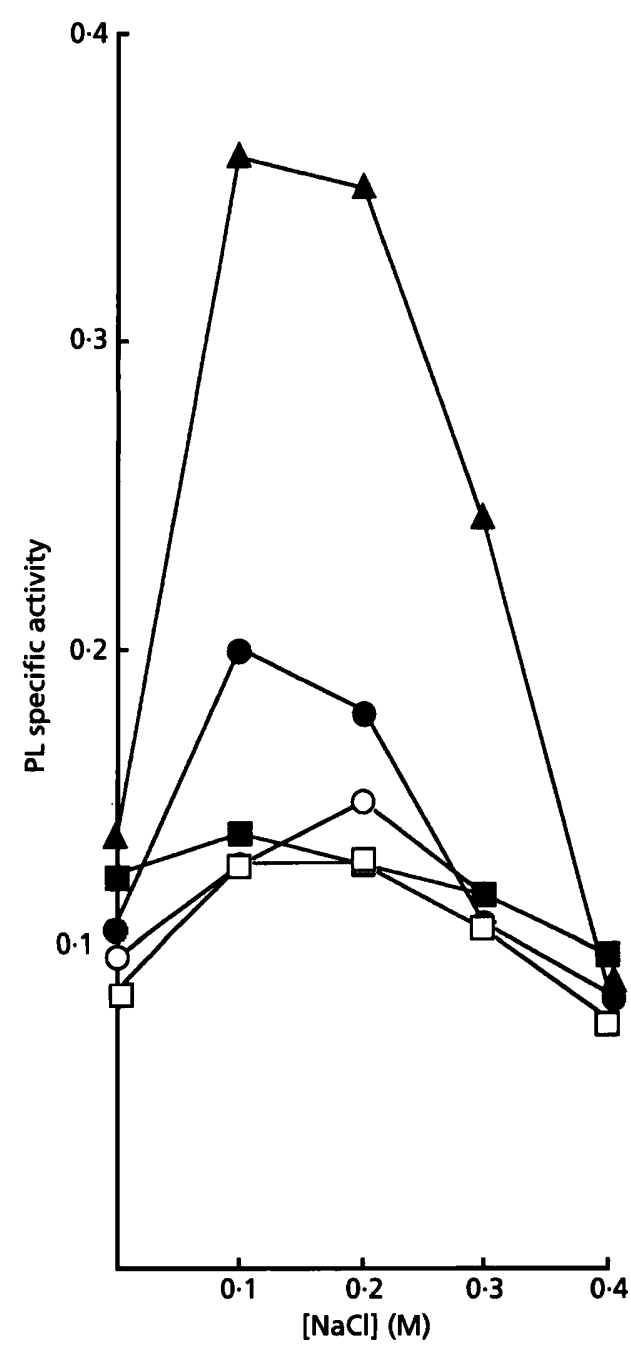

Fig. 2. Influence of $\mathrm{NaCl}$ concentration and osmoprotectants on the production of PL. Cells were grown in M63 medium containing various concentrations of $\mathrm{NaCl}$, in the absence of osmoprotectant ( $\Delta)$, or in the presence of (all $1 \mathrm{mM}$ ) glycine betaine $O$, proline $(O)$, ectoine $(\square)$ or pipecolate $(\square)$. Specific activity is expressed as $\mu \mathrm{mol}$ unsaturated products liberated $\min ^{-1}(\mathrm{mg} \text { dry } w t)^{-1}$.

osmoprotectants showed that all the osmoprotectants tested were accumulated in the cell and represented the main molecule, since only their specific signals were observed. The level of accumulation of each osmoprotectant was analysed in medium of increasing osmolarity containing $1 \mathrm{mM}{ }^{14} \mathrm{C}$-labelled osmoprotectant. In each case, the ethanolic soluble fraction containing radioactivity was quantified by scintillation counting (Fig. 1). Since these solutes are not metabolized by the cell, except for proline, the incorporated radioactivity corresponded to the accumulated molecule. The amount of proline determined by HPLC was similar to that deduced from scintillation counting of the proline spot. The intracellular content of each compound increased with medium osmolarity. In cells grown in medium deprived of $\mathrm{NaCl}$ (Fig. 1), the content of all molecules was $50-80 \mathrm{nmol}(\mathrm{mg} \text { dry } \mathrm{wt})^{-1}$. In contrast, this accumulation increased with medium osmolarity to $1.9,1 \cdot 3,1 \cdot 2$ and $1.5 \mu \mathrm{mol}$ (mg dry wt) ${ }^{-1}$ for glycine betaine, proline, ectoine and pipecolate, respectively, in medium containing $0.7 \mathrm{M} \mathrm{NaCl}$. For all the $\mathrm{NaCl}$ concentrations tested, the glycine betaine content was greater than that of the other osmoprotectants.

\section{Induction of PL production by osmolarity and its reversion by osmoprotectants}

Total PL production was assayed in medium containing $0-0.7 \mathrm{M} \mathrm{NaCl}$ in the absence or the presence of $1 \mathrm{mM}$ glycine betaine, proline, ectoine or pipecolate. In the absence of provided osmoprotectant, PL production first increased with increasing medium osmolarity, reaching a maximum at $0.2 \mathrm{M} \mathrm{NaCl}$, and then decreased progressively to the basal level at $0.4 \mathrm{M} \mathrm{NaCl}$ (Fig. 2). All the osmoprotectants tested reversed the increase in PL production that was induced by $\mathrm{NaCl}$. This reversion was not complete with $1 \mathrm{mM}$ proline but, in the presence of the other osmoprotectants, PL production was not significantly affected by increasing $\mathrm{NaCl}$ concentration.

To determine whether the PL induction observed with $\mathrm{NaCl}$ was a reflection of osmotic strength rather than being $\mathrm{NaCl}$-specific, we tested PL production in medium of similar osmotic strength using $0.3 \mathrm{M} \mathrm{NaCl}, 0.3 \mathrm{M} \mathrm{KCl}$, $0.48 \mathrm{M}$ mannitol or $0.41 \mathrm{M}$ glycerol as osmotic agents. PL production increased from $0.04 \mathrm{U}$ in absence of added osmolyte to $0 \cdot 27,0.41$ and $0.17 \mathrm{U}$ in the presence of $\mathrm{NaCl}$, $\mathrm{KCl}$ or mannitol, respectively. The addition of glycerol did not modify the specific activity of PL. The different osmoprotectants reversed PL induction in the presence of $\mathrm{KCl}$ or mannitol, but had no effect on PL production by cells grown in glycerol-containing medium (data not shown). Thus, activation of PL production resulted mainly from osmotic pressure. Additional ionic effects could not be excluded since better induction was observed with salts than with mannitol. This effect was not related to growth rate since this latter was unaffected by $\mathrm{NaCl}$ levels that were effective for PL induction. With regard to PL production under osmotic stress, strain 3937 behaved quite differently from the other $E$. chrysanthemi strains tested. Mildenhall $e$ t al. (1981) and Mildenhall \& Prior (1983) showed that only salts, and not organic solutes, were able to modify PL activity. With strain 3937, we did not observe a reduction in extracellular PL activity at any $\mathrm{NaCl}$ content as was reported by Prior $e$ t al. (1994). However, the effect observed by Prior et al. (1994) was mainly at the level of PL secretion; in our study, we always tested the total level and not only the extracellular fraction. The effect of osmoprotectants on PL activity that we observed also conflicts with the results of Prior $e t$ al. (1994), since we observed a reduction in PL activity instead of an increase. However, different isolates of $E$. chrysanthem $i$ were used and some differences could result from strain specificity. Mildenhall et al. (1981) and Mildenhall \& Prior (1983) reported that the nature of the medium and the osmolytes used may profoundly influence the results. They concluded that the effect of the water activity adjuster is not limited solely to water removal. It 
seems possible that both water activity and osmolarity can influence PL production. Nevertheless, we propose that the increase in PL production in strain 3937 does not result from the reduction of water activity but is stimulated by the osmotic pressure, since glycerol, which does not modify the intracellular pressure, had no effect on PL production. In this context, the effect of osmoprotectants could be explained by the recovery of cellular turgor resulting from their accumulation.

\section{In vitro effect of osmolytes and osmoprotectants on PL activity}

The effect of osmolarity on PL activity was analysed in vitro after incubation of crude extracts with $0.3 \mathrm{M} \mathrm{NaCl}$, $0.3 \mathrm{M} \mathrm{KCl}, \quad 0.48 \mathrm{M}$ mannitol or $0.41 \mathrm{M}$ glycerol for $30 \mathrm{~min}$ prior to enzyme assay. Elevated osmolyte concentrations can not be used directly in the assay medium because they provoke precipitation of the PL substrate, polygalacturonate. PL activity decreased by about $30 \%$ after incubation in the presence of $\mathrm{NaCl}$ or $\mathrm{KCl}$. In contrast, the presence of mannitol or glycerol enhanced PL activity, by about $20 \%$. High salt concentration probably affects the stability of the PL proteins while organic solutes protect the enzymes. The influence of $1 \mathrm{mM}$ osmoprotectants, glycine betaine, proline, ectoine or pipecolate, added alone or in the presence of osmolytes, was analysed. No significant effect on PL activity was observed. Thus, osmoprotectants at low concentrations do not affect the activity of PL excreted into the growth medium.

The effect of osmolytes on in vitro enzymic activity may be due to an effect on one or more PL isoenzymes. A specific inhibition by salts was observed, but both mannitol and glycerol slightly enhanced PL activity. Most of the enzymes that are sensitive to medium osmolarity (Pollard \& Wyn Jones, 1979; Arakawa \& Timasheff, 1985; Gouesbet $e$ t al., 1993) are inhibited by ionic strength rather than by water activity. The in vitro reversion of the salt effect was tested with low concentrations of osmoprotectants. Since PLs are secreted by E. chrysanthemi into the medium, they may be naturally exposed to low concentrations of these compounds but not to the high concentrations found in the intracellular compartment. Thus, there is no biological significance in testing higher concentrations of osmoprotectants such as those used for intracellular enzymes (Arakawa \& Timasheff, 1985; Gouesbet et al., 1993). We conclude that osmoprotectant effects on PL activity are exerted only at the level of enzyme production.

\section{Effects of osmolarity and osmoprotectants on pelE expression}

It was previously reported that among the pel genes, only $p e l E$ transcription was induced by the presence of $0.3 \mathrm{M}$ $\mathrm{NaCl}$ in growth medium (Hugouvieux-Cotte-Pattat et al., 1992). We tested the influence of $0-0.7 \mathrm{M} \mathrm{NaCl}$ on pelC: :uid $A$ and pelE: :uid $A$ transcriptional fusion activities. The expression of pelC: : uid $A$ was not affected

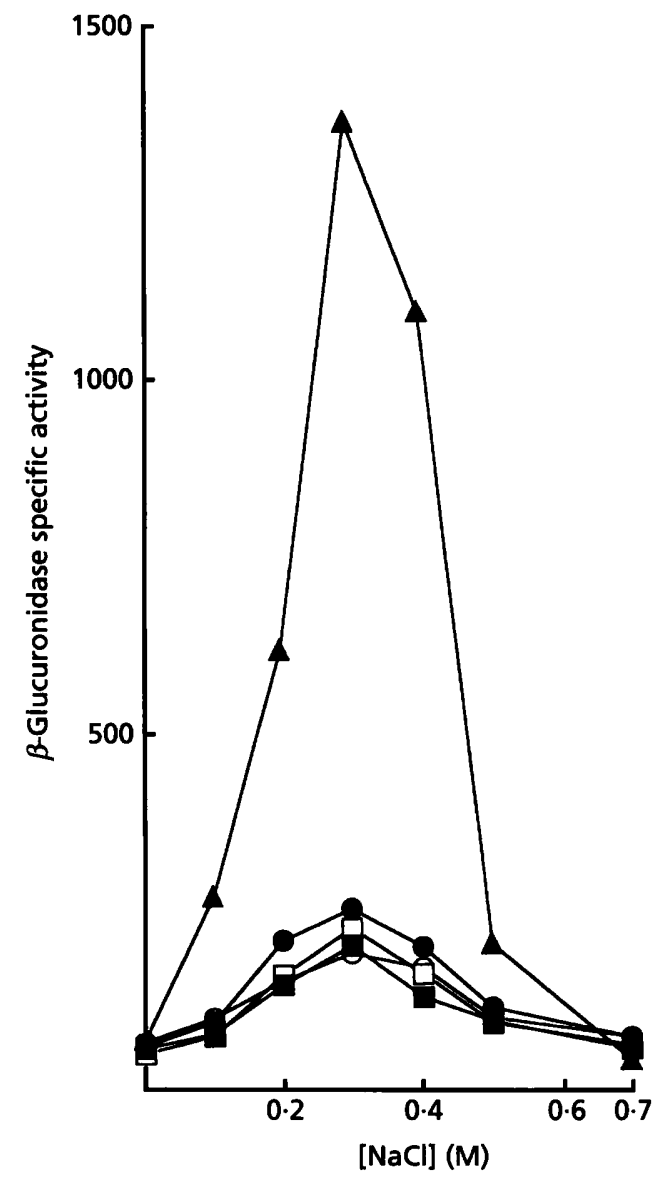

Fig. 3. Influence of medium osmolarity and osmoprotectants on the expression of the pelE: : uidA fusion. Cells were grown in M63 medium containing $\mathrm{NaCl}$ at the indicated concentration and deprived of $(\Delta)$ or containing $1 \mathrm{mM}$ of glycine betaine $(O)$, proline (O), ectoine $(\square)$ or pipecolate $(\square)$. After 10 generations in the same medium, cells were collected in the late exponential-phase and $\beta$-glucuronidase, reflecting the expression of the fusion, was assayed. Specific activity is expressed as nmol $p$-nitrophenol liberated $\min ^{-1}(\mathrm{mg} \text { dry } \mathrm{wt})^{-1}$.

by increasing the medium osmolarity up to $0.7 \mathrm{M} \mathrm{NaCl}$, since the specific activity of $\beta$-glucuronidase was $150 \mathrm{U}$ for every $\mathrm{NaCl}$ concentration. Similarly, the presence of $1 \mathrm{mM}$ glycine betaine, proline, ectoine or pipecolate had no influence on pelC: : uid $A$ expression (data not shown). In contrast, $p e l E:$ uid $A$ transcription was induced by $\mathrm{NaCl} ; \beta$-glucuronidase activity was maximal at $0.3 \mathrm{M}$ $\mathrm{NaCl}$ and then decreased slowly up to $0.7 \mathrm{M} \mathrm{NaCl}$ (Fig. 3). The presence of $1 \mathrm{mM}$ osmoprotectants in the growth medium reversed the induction by $\mathrm{NaCl}$ (Fig. 3).

As observed for $\mathrm{PL}$ production, the induction of pelE: : uid $A$ could be achieved by osmolytes other than $\mathrm{NaCl}$. The addition of $\mathrm{KCl}$ or mannitol into the medium at a concentration corresponding to $825-866 \operatorname{mosM}$, resulted in the induction of pelE: : uid $A$ expression (Table 1 ). As for PL, $\beta$-glucuronidase specific activity was greater for cells grown with $\mathrm{NaCl}$ or $\mathrm{KCl}$ than for cells issued from mannitol-containing medium. When medium osmo- 
Table 1. Influence of $\mathrm{NaCl}, \mathrm{KCl}$, mannitol and glycerol on pelE: : uidA expression

Cells were grown for 10 generations in the same M63 medium containing $0.3 \mathrm{M} \mathrm{NaCl}(825 \operatorname{mos} \mathrm{M}), 0.3 \mathrm{M} \mathrm{KCl}(875 \mathrm{mosM})$, $0.5 \mathrm{M}$ mannitol (866 mosM) or $0.5 \mathrm{M}$ glycerol (1002 mosM). Specific activity is expressed as nmol $p$-nitrophenol liberated $\min ^{-1}$ (mg dry $\left.w t\right)^{-1}$.

\begin{tabular}{|lrrrc|}
\hline $\begin{array}{l}\text { Osmoprotectant } \\
(\mathbf{1} \text { mM) }\end{array}$ & \multicolumn{4}{c|}{ Specific activity of $\boldsymbol{\beta}$-glucuronidase } \\
& with: \\
\cline { 2 - 5 } & $\mathbf{N a C l}$ & $\mathbf{K C l}$ & Mannitol & Glycerol \\
\hline None & 1360 & 1070 & 790 & 50 \\
Glycine betaine & 190 & 120 & 70 & 50 \\
Proline & 250 & 150 & 120 & 60 \\
Ectoine & 220 & 140 & 80 & 60 \\
Pipecolate & 200 & 160 & 90 & 60 \\
\hline
\end{tabular}

larity was increased with the permeant molecule glycerol, no variation in $\beta$-glucuronidase activity was observed. The effects of the various osmolytes was reversed by osmoprotectants, as was the case for $\mathrm{NaCl}$-induced expression. Thus, reversion is not specific to the osmolyte, but probably results from the recovery of intracellular turgor pressure induced by osmoprotectant accumulation. We could exclude the fact that osmoprotectants act independently of turgor since they have no effect when present in medium deprived of osmolyte, or when added to medium containing $0.5 \mathrm{M}$ glycerol.

Since total PL production follows this regulatory pattern, it is tempting to speculate that increase in PL activity could be attributed only to the isoenzyme PLe. Various PL isoenzymes are produced in all E. chrysanthemi strains. The divergence of our results with those of Prior et al. (1994) could result from a different proportion of PL isoenzymes in the $E$. chrysanthemi strains used. We observed, as described for formate dehydrogenase in $E$. coli (Gouesbet $e t$ al., 1993), a shift between the response of gene expression and enzyme production as osmolarity increased. This result implies that, as for formate dehydrogenase synthesis in E. coli, osmoregulation of PL production in $E$. chrysanthemi is exerted both at the transcriptional and post-transcriptional level. As reported by Prior et al. (1994), PL secretion is affected by medium osmolarity. Other steps in PL maturation or folding may also be influenced by osmolarity.

Higher induction of PL activity was obtained with $\mathrm{KCl}$, but $\mathrm{NaCl}$ was more efficient at inducing $p e l E$ expression. In most bacteria, $\mathrm{KCl}$ induces a lower osmotic response than $\mathrm{NaCl}$, probably because $\mathrm{K}^{+}$accumulation could partially reverse the stress by increasing free cytoplasmic water (Cayley et al., 1992). The greater PL activity in the presence of $\mathrm{KCl}$ could be attributed to an effect of $\mathrm{K}^{+}$on the secretion of PL, or its maturation or folding in the periplasmic space (Shevchik et al., 1994). The osmoinduction of $p e l E$ could be stimulated by $\mathrm{K}^{+}$as described for E. coli genes (Ramirez et al., 1989; Booth, 1993). Since osmoprotectants are accumulated within the cell, their effect on pelE expression could be attributed to an efflux of $\mathrm{K}^{+}$, as observed previously in E. coli (Cayley et al., 1992; Gouesbet et al., 1993). pelE expression was also shown to be stimulated by anaerobiosis (Hugouvieux-Cotte-Pattat et al., 1992), so DNA supercoiling may also be involved in its regulation, as is the case for other genes stimulated both by osmolarity and by anaerobiosis (Dorman et al., 1988; Gouesbet et al., 1993).

\section{ACKNOWLEDGEMENTS}

We thank Valerie James for correcting the English in this paper, and Guy Condemine, Sylvie Reverchon and Théophile Bernard for their interest in this work. This work was supported by grants from the Centre National de la Recherche Scientifique, the Ministère de la Recherche et de la Technologie, the Direction de la Recherche et des Etudes Doctorales and the Région Bretagne (programme BRIT'TA).

\section{REFERENCES}

Arakawa, T. \& Timasheff, S. N. (1985). The stabilization of proteins by osmolytes. Biophys $J$ 47, 411-414.

Bernard, T., Jebbar, M., Rassouli, Y., Himdi-Kabbab, S., Hamelin, J. \& Blanco, C. (1993). Ectoine accumulation and osmotic regulation in Brevibacterium linens. J Gen Microbiol 139, 129-136.

Booth, I. R. (1993). Regulation of gene expression during osmoregulation: the role of potassium glutamate as a secondary signal of osmotic stress. In Alkali Cation Transport Systems in Prokaryotes, vol. 2, pp. 309-331. Edited by E. P. Bakker. Boca Raton, FL: CRC Press.

Cayley, S., Lewis, B. A. \& Record, M. T. (1992). Origins of the osmoprotective properties of betaine and proline in Escherichia coli K-12. J Bacteriol 174, 1586-1595.

Colhoun, J. (1973). Effects of environmental factors on plant disease. Annu Rev Phytopatbol 11, 343-364.

Csonka, L. N. (1989). Physiological and genetic responses of bacteria to osmotic stress. Microbiol Rev 53, 121-147.

Csonka, L. N. \& Hanson, A. D. (1991). Prokaryotic osmoregulation: genetics and physiology. Annu Rev Microbiol 45, 569-606.

Dorman, C. J., Barr, G. C., Ni Bhriain, N. \& Higgins, C. F. (1988). DNA supercoiling and the anaerobic and growth phase regulation of tonB gene expression. J Bacteriol 170, 2816-2826.

Gouesbet, G., Blanco, C., Hamelin, J. \& Bernard, T. (1992). Osmotic adjustment in Brevibacterium ammoniagenes: pipecolic acid accumulation at elevated osmolalities. J Gen Microbiol 138, 959-965.

Gouesbet, G., Abaibou, H., Wu, L. F., Mandrand-Berthelot, M. A. \& Blanco, C. (1993). Osmotic repression of anaerobic metabolic systems in Eschericbia coli. J Bacteriol 175, 214-221.

Hoppe, P. E. \& Kelman, A. (1969). Bacterial top and stalk rot disease of corn in Wisconsin. Plant Dis Rep 53, 66-70.

Hugouvieux-Cotte-Pattat, N., Dominguez, H. \& Robert-Baudouy, H. (1992). Environmental conditions affect transcription of the pectinase genes of Erwinia chrysanthemi 3937. J Bacteriol 174, 7807-7818. 
Ikuta, S., Matuura, K., Imamura, S., Misaki, H. \& Horiuti, Y. (1977). Oxidative pathway of choline to betaine in the soluble fraction prepared from Artbrobacter globiformis. J Biochem 82, 157-163.

Jebbar, M., Talibart, R., Gloux, K., Bernard, T. \& Blanco, C. (1992). Osmoprotection of Escherichia coli by ectoine: uptake and accumulation characteristics. J Bacteriol 174, 5027-5035.

Kotoujansky, A. (1987). Molecular genetics of pathogenesis by soft-rot Erwinia. Annu Rev Pbytopathol 25, 405-430.

Mildenhall, J. P. \& Prior, B. A. (1983). Water relations of Erwinia chrysanthemi: intracellular and extracellular pectate lyase production. $J$ Gen Microbiol 129, 3019-3025.

Mildenhall, J.P., Prior, B. A. \& Trollope, L. A. (1981). Water relations of Erwinia chrysanthemi: growth and extracellular pectic acid lyase production. J Gen Microbiol 127, 27-34.

Miller, J. H. (1972). Experiments in Molecular Genetics. Cold Spring Harbor, NY: Cold Spring Harbor Laboratory.

Pollard, A. \& Wyn Jones, R. G. (1979). Enzyme activities in concentrated solutions of glycine betaine and other solutes. Planta 144, 291-298.
Prior, B. A., Hewitt, E., Brandt, E. V., Clarke, A. \& Mildenhall, J. P. (1994). Growth, pectate lyase production and solute accumulation by Erwinia chrysanthemi under osmotic stress: effect of osmoprotectants. J Appl Bacteriol 77, 433-439.

Ramirez, R. M., Prince, W. S., Bremer, E. \& Villarejo, M. (1989). In vitro reconstitution of osmoregulated expression of proU of Escherichia coli. Proc Natl Acad Sci US A 86, 1153-1157.

Shevchik, V. E., Condemine, G. \& Robert-Baudouy, J. (1994). Characterization of DsbC, a periplasmic protein of Erwinia chrysanthemi and Escherichia coli with disulfide isomerase activity. EMBO J 13, 2007-2012.

Talibart, R., Jebbar, M., Gouesbet, G., Himdi-Kabbab, S., Wroblewski, H., Blanco, C. \& Bernard, T. (1994). Osmoadaptation in rhizobia: ectoine-induced salt tolerance. $J$ Bacteriol 176, $5210-5217$.

Received 28 October 1994; revised 31 January 1995; accepted 22 February 1995. 